\title{
Assessment of Freeze-Thaw Cycles Impact on Flexural Tensile Characteristics of Asphalt Mixture in Cold Regions
}

\author{
Cidan Duojie, ${ }^{1}$ Wei Si $\mathbb{C}^{,},{ }^{1}$ Biao Ma, ${ }^{1}$ Yongping Hu, ${ }^{1}$ Xue Liu, ${ }^{2}$ and Xintong Wang ${ }^{3}$ \\ ${ }^{1}$ Key Laboratory for Special Area Highway Engineering of Ministry of Education, Chang'an University, Xi'an 710064, China \\ ${ }^{2}$ School of Data and Computer Science, Sun Yat-sen University, Guangzhou 510275, China \\ ${ }^{3}$ School of Humanities and Social Science, Hong Kong University of Science and Technology, Clear Water Bay, Kowloon, \\ Hong Kong 999077, China \\ Correspondence should be addressed to Wei Si; siwei@chd.edu.cn
}

Received 22 November 2020; Revised 27 December 2020; Accepted 4 February 2021; Published 17 February 2021

Academic Editor: Mijia Yang

Copyright ( 2021 Cidan Duojie et al. This is an open access article distributed under the Creative Commons Attribution License, which permits unrestricted use, distribution, and reproduction in any medium, provided the original work is properly cited.

\begin{abstract}
Low average temperature, large temperature difference, and continual freeze-thaw cycles have significant impacts on mechanical property of asphalt pavement. Bending test was applied to illustrate the mixtures' flexural tensile properties under freeze-thaw (FT) conditions. Experiment results showed that the flexural tensile strength and strain declined as F-T cycles increased; the deterioration of flexural tensile properties decreased sharply during initial F-T cycles but turned smooth after 15-21 F-T cycles. ANOVA showed that F-T cycles, asphalt-aggregate ratio, and gradation had obvious influence on flexural tensile characteristics. Flexural characteristics of AC-13 behaved better than the other gradations. It turned out that the mixtures' low-temperature bending characteristics were improved when 5.5\% optimum asphalt-aggregation ratio or slightly larger AC-13 gradation was applied.
\end{abstract}

\section{Introduction}

Qinghai-Tibet Plateau (QTP), located in the southwest of China, has an average altitude over $4000 \mathrm{~m}$. It is the largest plateau in China with permafrost widely distributed. QTP has capricious climates and complex geological conditions, which are different from other ordinary regions [1-3]. In QTP, the mean annual air temperature is under $0^{\circ} \mathrm{C}$ : a transient period as temperature goes over $0^{\circ} \mathrm{C}$ from July to August, under $0^{\circ} \mathrm{C}$ from November to the following March, and changeable around $0^{\circ} \mathrm{C}$ in the remaining days, during which period the temperature gap between day and night is sharp, with a maximum temperature gap up to $26^{\circ} \mathrm{C}$ [4-6]. Additionally, the solar radiation is higher than $3600 \mathrm{KJ} / \mathrm{m}^{2}$. Cooling and heating rates are rapid; thus, the asphalt pavement in this area suffers more frequent freeze-thaw (FT) cycles compared with other regions.

Qinghai-Tibet Highway (QTH) passes through the QTP from north to south, of which the pavement is semirigid base asphalt concrete (AC) and the general structure is $4 \mathrm{~cm} \mathrm{AC-}$
$13+6 \mathrm{~cm}$ AC- $16+20 \mathrm{~cm}$ cement stabilized macadam base. QTH suffers from the severe environment conditions such as low annual average temperature, large difference in temperature, rapid cooling rate, and frequent and violent F-T cycles [7-10]. All these adverse weather conditions have evident influences on mechanical property and durability of asphalt pavement [11].

Asphalt is a thermoplastic material with asphalt concrete mixtures, property of which is sensitive as temperature changes, with viscoelastic characteristic. Distresses in cold regions are more complex and serious than those in normal areas. Distresses like settlement, nonuniform deformation, and thermal cracks are critical for highway in cold regions, especially in QTH [12-14]. Numerous studies have found that distresses of highway have significant relationships with local special climate and environment conditions as well as loads.

By investigating the operation and distress of QTH, researchers found that there were serious distresses and damages, especially various cracks along the highway. As 
shown in Figure 1, there are many serious longitudinal and transverse cracks in the highway pavement and trends to form map cracking. It is known that transverse cracks in cold regions are generally caused by lower temperature and rapid cooling, that is, F-T cycles effect. F-T effect has obvious impacts on asphalt pavement performance as well as the pavement lifecycle $[15,16]$.

Asphalt pavement is exposed in atmosphere; when temperature falls rapidly or there is continuous low temperature, thermal stress in asphalt pavement forms. If the stress relaxation of asphalt pavement is larger than comprehensive stress growth (including temperature stress and load stress), there is no obvious distress in the appearance, but the interior microdamage of pavement will be accumulated. When there is comprehensive stress over the ultimate tensile strength of asphalt mixture, cracks and other distresses will arise [17]. Moreover, when pavement is in moisture environment, hydrodynamic pressure and vacuum constriction will appear in the surface layer under repeatable loads. This leads to the surface AC stripping aggravation and voids increase. Finally, the asphalt mixture becomes loose and cracks are formed from initial tiny damage, which is caused by the complicated effects including the migration, accumulation, and freezing of water in asphalt mixture and displacement of water in asphalt film $[18,19]$. Consequently, the increasing of F-T cycles or continuous low temperature will speed up the damage and become more harmful to AC structures.

Asphalt pavement suffered from the impact of F-T in cold regions worldwide, and how to precisely evaluate the influence of F-T cycles on flexural characteristics has become one of the daunting tasks [20]. To solve this problem, lowtemperature bending property of asphalt mixture under different F-T cycles had been applied in this research, and the influences of aggregate ratio and gradation were also analyzed.

The objectives of this research are to analyze the flexural tensile characteristics of AC under F-T cycles and to evaluate the impact factors on asphalt-aggregate ratio, gradation, and F-T cycles. The results provided a good reference for asphalt mixture design, distress prevention, and some scientific guidelines for highway construction and maintenance in cold regions.

\section{Materials and Experimental Methods}

2.1. Materials Used. The materials used in this study are listed below. The type of asphalt used was styrene butadiene rubber (SBR) modified asphalt supplied by Jinshi in Xinjiang, China, which is frequently used in QTP. Test results are presented in Table 1. Aggregates and mineral powders were obtained from lime-stone Haihong rock quarry in Tibet, China.

Asphalt mixtures used in this research were AC-10, AC13, and AC-16, and gradation composition of aggregates mixture recommended by specification of Ministry of Transportation of China was given in Table 2 .

The optimum asphalt content of the asphalt mixture was obtained by Marshall Test [21]. On the basis of Marshall Test and considering the special climate and traffic condition in cold QTP, the final optimum asphalt contents (OAC) of the three asphalt mixtures AC-10, AC-13, and AC-16 are 5.0\%, $5.5 \%$, and $6.0 \%$, respectively.

2.2. F-T Cycle Test. At first, F-T cycle test used in civil engineering is to evaluate the impact of F-T cycles on the performance of cement concrete [22] and soil [23, 24]. As the application of flexural pavement increases in cold regions and the unusual distresses appear, some researchers noticed that asphalt pavement also suffered from F-T cycles influence. There is a big difference between viscoelastic characteristics of asphalt concrete and cement concrete elastic property. Some researches have been conducted on the F-T performance of asphalt mixtures [25].

In terms of AC F-T cycle test, there is no standard due to the differences in climate among different cold areas. In AASHTO 283 testing procedure, each vacuum saturated specimen was tightly covered with plastic wrap and placed in a plastic bag with approximately $10 \pm 0.5 \mathrm{~mL}$ of water and then sealed; the plastic bags were placed in a freezer at $-18 \pm 3^{\circ} \mathrm{C}$ for $24 \mathrm{~h}$ and then removed to a water bath at $60 \pm 1^{\circ} \mathrm{C}$ for $24 \mathrm{~h}$ and finally placed in a water bath at $25 \pm 0.5^{\circ} \mathrm{C}$ for $2 \mathrm{~h} \pm 10 \mathrm{~min}$ to achieve room temperature [26]. In one research, the samples were soaked in water for $12 \mathrm{~h}$ at room temperature; then each was covered with plastic wrap, sealed in a plastic bag, and placed in an environmental chamber for $12 \mathrm{~h}$ at $-17.8^{\circ} \mathrm{C}$. The conditioned samples were exposed to seven $24 \mathrm{~h}$ cycles [27]. In another research, the specimens were firstly water-conditioned by vacuum saturation for $15 \mathrm{~min}$ and then subjected to 8 successive cycles of freezing and thawing. Each cycle was consisted of freezing at $-20^{\circ} \mathrm{C}$ for $8 \mathrm{~h}$ followed by soaking in water at $60^{\circ} \mathrm{C}$ for $4 \mathrm{~h}$ [28].

Meteorological data in QTH show that annual average lowest temperature is among $-14.5^{\circ} \mathrm{C}$ to $-17.4^{\circ} \mathrm{C}$, annual average highest temperature is $6.8^{\circ} \mathrm{C}$ to $8.1^{\circ} \mathrm{C}$, and the maximum temperature difference between day and night can reach a range between $23^{\circ} \mathrm{C}$ and $26^{\circ} \mathrm{C}$, which indicates that it has a rapid cooling and heating rate. Considering present F-T test, a modified F-T test was proposed according to the practical climate conditions of QTH in this paper. The test uses plastic bag to seal up each specimen and injects $30 \mathrm{ml}$ water to the plastic bag when freezes. Freezing temperature is $-25 \pm 1^{\circ} \mathrm{C}$ and freezing lasts $12 \mathrm{~h}$; then the specimens are put in a water bath to be thawed at $25 \pm 1^{\circ} \mathrm{C}$ and the thawing lasts $12 \mathrm{~h}$. The freezer and water bath are used to simulate the F-T cycles.

Fresh mixed asphalt mixtures are shaped up by Wheel Grinding Method into slabs that are $300 \mathrm{~mm}$ in length and width and $50 \mathrm{~mm}$ in height. The slabs are then cut into prism beam that is $250 \mathrm{~mm} \pm 2.0 \mathrm{~mm}$ in length, $30 \mathrm{~mm} \pm 2.0 \mathrm{~mm}$ in width, and $35 \mathrm{~mm} \pm 2.0 \mathrm{~mm}$ in height by cutter. The mixture flexural tensile laboratory test was carried out by Universal Material Tester System (UMTS) performed by three-point bending test, and the loads and deformations were automatically measured by computer. The UMTS is a computercontrolled system that can operate automatically. Loads and 

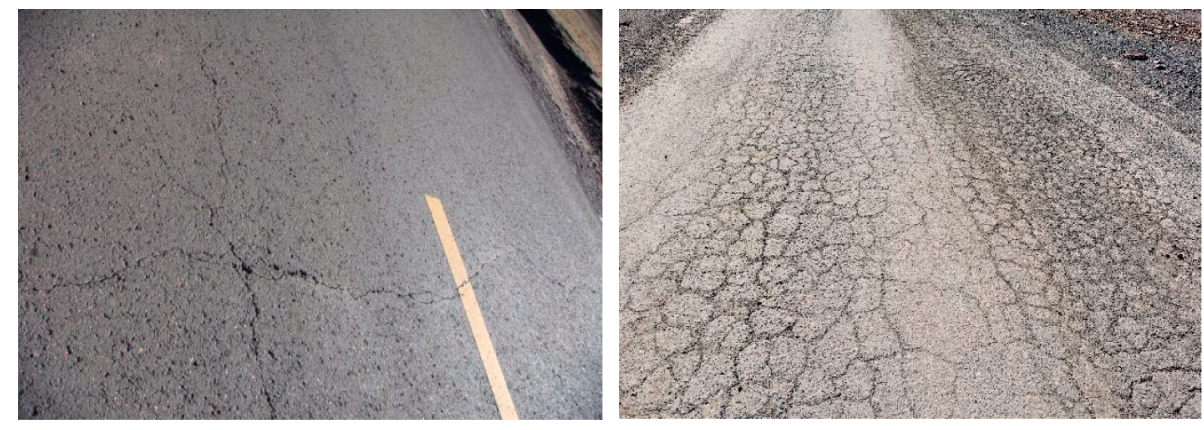

Figure 1: Crack distresses in Qinghai-Tibet Highway.

TABLE 1: Test results of asphalt parameters.

\begin{tabular}{lccc}
\hline Asphalt state & Test item & Results \\
\hline \multirow{4}{*}{ Original sample } & Penetration $/ 0.1 \mathrm{~mm}$ & $15^{\circ} \mathrm{C}$ & 51 \\
& Softening point $(\mathrm{R} \& \mathrm{~B}) /{ }^{\circ} \mathrm{C}$ & $25^{\circ} \mathrm{C}$ & 123 \\
& Ductility $/ \mathrm{cm}$ & 57.6 \\
& Density $/ \mathrm{g} \cdot \mathrm{cm}^{-3}$ & & $>150$ \\
& Flashing point $/{ }^{\circ} \mathrm{C}$ & 1.023 \\
& Solubility $/ \%$ & $>260$ \\
After aging & Mass loss $/ \%$ & 99.6 \\
\hline & Vestigial penetration ratio $/ \%$ & $15^{\circ} \mathrm{C}$ & 6.2 \\
& & $25^{\circ} \mathrm{C}$ & 58.1 \\
& Ductility $/ \mathrm{cm}$ & $5^{\circ} \mathrm{C}$ & $>150$ \\
\hline
\end{tabular}

deflection of specimen were measured by load cells and linear variable differential transducers (LVDTs), respectively. UMTS was equipped with environment chamber with an accuracy of $\pm 0.1{ }^{\circ} \mathrm{C}$, and loading speed could be chosen according to the needs of the experiment. The purpose of flexural tensile under F-T cycles testing is to evaluate asphalt mixture's bending failure property, temperature, and moisture susceptibility.

When three-point bending test under low temperature was conducted, $-10 \pm 0.5^{\circ} \mathrm{C}$ and $50 \mathrm{~mm} / \mathrm{min}$ were applied as test temperature and load speed, respectively. After samples were tested by bending test under F-T cycles, the bending performance of asphalt mixture was evaluated by failure flexural strength and failure flexural strain, which are calculated by the following formulas [21]:

$$
\begin{aligned}
R_{B} & =\frac{3 \times L \times P_{B}}{2 \times b \times h^{2}}, \\
\xi_{B} & =\frac{6 \times h \times d}{L^{2}},
\end{aligned}
$$

where $R_{B}$ is the failure flexural strength ( $\left.\mathrm{MPa}\right), L$ is distance between beam supports $(200 \mathrm{~mm}), P_{B}$ is the ultimate loading at failure $(\mathrm{N}), b$ is width of beam specimen $(30 \mathrm{~mm}), h$ is height of beam specimen $(35 \mathrm{~mm}), \xi_{B}$ is the failure flexural strain $(\mu \xi)$, and $d$ is the mid-span deflection at the specimen failure $(\mathrm{mm})$. Average value of three-specimen failure $(\mathrm{mm})$ and average value of three specimens for each F-T cycle condition test were applied to analyze the flexural tensile characteristics in this paper.

\section{Results and Discussion}

3.1. Impact of F-T Cycles. In order to explain F-T cycles' impact on mixture flexural characteristics, AC-13 asphalt mixture with OAC 5.5\% was taken for test. After $30 \mathrm{~F}-\mathrm{T}$ cycles, the tendencies of flexural tensile strength and flexural tensile strain are shown in Figure 2.

Figure 2 shows that flexural tensile strength and tensile strain tend to decline with F-T cycles increasing. In initial F-T cycles, flexural characteristics drop significantly; after 9 F-T cycles, the decline of flexural tensile characteristics becomes gentle. Through 15 to $21 \mathrm{~F}$-T cycles, the degradation tendency is gradually stable. After $30 \mathrm{~F}-\mathrm{T}$ cycles, the flexural tensile strength reduces nearly $4 \mathrm{MPa}$ compared with unconditioned (no F-T cycle) performance, the attenuation reaches $27 \%$, and the flexural tensile strain attenuates $12.6 \%$.

Under the repetitive F-T cycles, mixture internal pores and air voids are increased. Water enters into the asphalt membrane easily and decreases the bond force between asphalt membrane and aggregate, which leads the mixture to be easily broken. When AC is in moisture environment, especially in saturated condition, its air voids will be filled with water. This water turns into ice in freezing cycles, causing the ice volume expansion. The internal of the mixture generates expansion force and results in microdamage to mixture [28]. During the thaw cycles, with the filled ice melting, more water will permeate through air voids and internal pores, and the bonding between asphalt membrane and aggregates decreases as the water erodes $[27,29]$. The bond force declines rapidly after repetitive F-T cycles. Results indicate that F-T cycles in the early years have obvious influence on asphalt mixture flexural performance. So, the early damage of asphalt pavement in cold regions is more frequent and serious than in other regions.

Due to the uneven distribution of aggregate, defects of internal structure, and increment of F-T cycles, the mixture's internal damage gradually increases and finally fractures in the loading test. Therefore, the mixture's flexural tensile strength is related to mixture porosity, coarse aggregate distribution, and internal structure defects.

Figure 3 illustrates that mixture performance attenuated with F-T cycles increasing. However, there are still some abnormal points, which decrease sharply in a certain F-T cycles performance and inversely increase in the next F-T cycle. In terms of this phenomenon, the uneven aggregate 
TABLE 2: Gradation composition of aggregates mixture.

\begin{tabular}{lccccccccccc}
\hline \multirow{2}{*}{ Gradation } & \multicolumn{10}{c}{ Passing rate (\%) of sieve size (mm) } \\
& 19 & 16 & 13.2 & 9.5 & 4.75 & 2.36 & 1.18 & 0.6 & 0.3 & 0.15 & 0.075 \\
\hline AC-10 & - & - & 100 & 95 & 60 & 44 & 33 & 22.5 & 16 & 11 \\
AC-13 & - & 100 & 95 & 76.5 & 53 & 37 & 26.5 & 19 & 13.5 & 10 \\
AC-16 & 100 & 95 & 81 & 70 & 48 & 34 & 24.5 & 17.5 & 12.5 & 9.5 & 6 \\
\hline
\end{tabular}

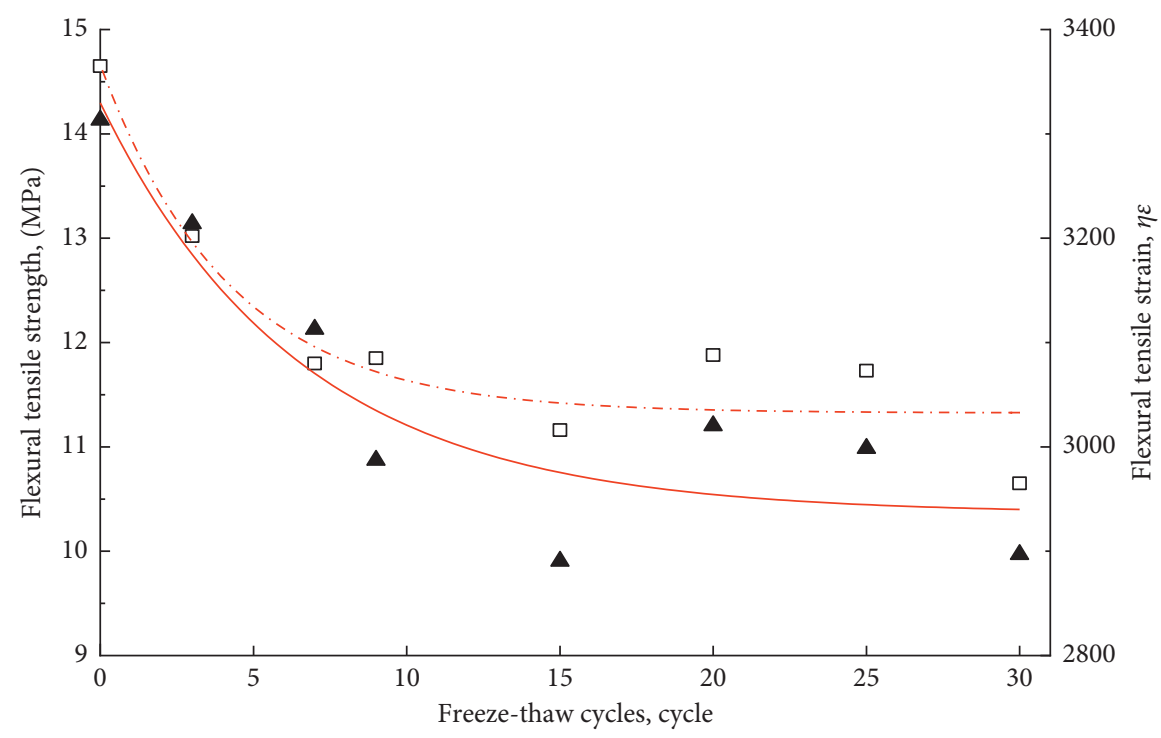

Strength

$\Delta$ Strain

-. - Exponential fit of strength

Exponential fit of strain

Figure 2: Relationship of flexural tensile characters and F-T cycles.

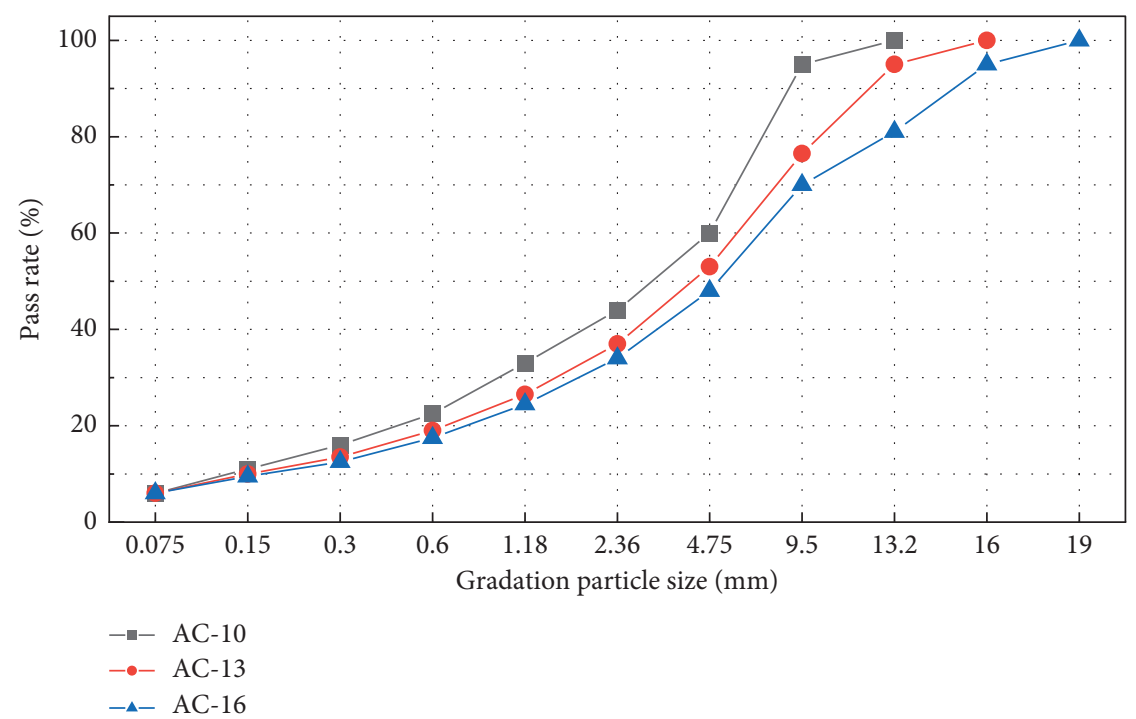

FIGURE 3: Grading curve. 
distribution (differences between the cut beams) may take main responsibility.

3.2. Exponential Model Fitting. Curves of flexural tensile strength and flexural tensile strain versus F-T cycles in Figure 2 present nonlinear variation, and the curves can be simulated by exponent or logarithm function. The exponential model is chosen to fit the flexural tensile characteristics variation in this paper. The formula used is as follows $[24,25]$ :

$$
y=a+b \cdot e^{c \times x}+\varepsilon, \quad \varepsilon \sim N\left(0, \delta^{2}\right),
$$

where $a$ is the constant term, which means the initial value of flexural tensile characteristics; $b$ is coefficient, which refers to the degradation speed; $c$ is coefficient, which refers to curvature of curves; $x$ is the explanatory variable, denoting F-T cycles here; $y$ is explained variable, representing flexural tensile characteristics (MPa); and $\varepsilon$ is the error term.

In this model, the error term is supposed to be approximately normally distributed. The variance of the error term $\delta^{2}$ is independent, homoscedastic, and identical across observations. The least-square method has been applied to parameter estimation, due to the $\varepsilon$ subjects to normal distribution; Chi-square has been used to assess the goodness of fit (GOF) of the exponential model. The equation is as follows $[24,25]$ :

$$
\chi^{2}=\sum_{i=1}^{n} w_{i}\left(y_{i}-\hat{y}_{i}\right)^{2}
$$

where $w_{i}$ is the weighting coefficient, which can be calculated by $w_{i}=\left(1 /\left(\sigma_{i}^{2}\right)\right) ; y_{i}$ is the experimental data point and $\hat{y}_{i}$ is the theoretical point; $n$ is the experimental number. This paper considers the measurement errors as unknown; $\sigma_{i}$ is set to 1 for all $i$ and the curve fitting is performed without weighting.

$R^{2}$ represents the fitting quality of models, which increases with adding variables to the model without enough information. Adjusted $R_{\text {adj }}^{2}$ (adj. R-square) is preferable as it has the advantage that it only increases if the added variable reduces the mean square error of the model.

Fitting results are shown in Table 3. Results show that the exponential model well reflects the variation of flexural tensile strength and flexural tensile strain with F-T cycles; the adj. R-square reaches 0.866 and 0.823 , respectively. The ANOVA method is used to analyze the fitting significance. The results are listed in Table 4 . The ANOVA results indicate that, at the 0.01 level, tensile characteristics and regression model have good relationship, and the exponential model can be used to simulate the mixture degradation under F-T cycles.

Impact of asphalt-aggregate ratio.

AC-13 was used as an example to illustrate the influence of asphalt-aggregate ratio on flexural characteristics under F-T cycles, with asphalt-aggregate ratio of $4.5 \%, 5.0 \%, 5.5 \%$, $6.0 \%$, and $6.5 \%$, respectively. Test results are shown in Figures 4(a) and 4(b).
Figure 4 shows that flexural tensile characteristics present as parabolic variation as the asphalt content increases. Tensile strength has more obvious parabolic variation than tensile stain; at the OAC (5.5\%), both tensile strength and stain attain the peak value. When asphaltaggregate ratio exceeds $\mathrm{OAC}$, tensile strength declines more sharply compared with tensile strain.

After $30 \mathrm{~F}$-T cycles, the flexural tensile strength of asphalt-aggregate ratio with $4.5 \%$ and $6.5 \%$ reduces by $3.2 \mathrm{MPa}$ and 1.1 MPa, respectively. For unconditioned mixture, the flexural tensile performance is significantly greater than others, and their performance decreases gradually with F-T cycles increasing. Compared with lower asphalt-aggregate ratio $(4.5 \%$ and $5.0 \%)$, the mixture's attenuation tendency of tensile strain is smaller with higher asphalt-aggregate ratio $(6.0 \%, 6.5 \%)$ under F-T cycles. Under the F-T cycle, compared with the lower asphalt-aggregate ratio $(4.5 \%$ and $5.0 \%)$, the higher the asphalt-aggregate ratio $(6.0 \%$ and $6.5 \%)$ is, the slower the tensile strain attenuation of the mixture will be.

Asphalt-aggregate ratio is closely related to the mixtures' porosity. The larger the asphalt-aggregate ratio is, the smaller mixture porosity is. Air voids and internal pores will expand as the filled water freezes in F-T cycles. Icy water in the pore causes a huge expansion force, which leads to the mixture internal structure deterioration and destruction.

If asphalt-aggregate ratio is too small, it is hard to form the thin asphalt membrane to bind aggregate particles. The bond force between asphalt and aggregate is not intense. Under temperature gradient, loading stress, and F-T cycles, the mixture structure becomes loose, which leads to decline of flexural characteristics. With asphalt-aggregate ratio increasing, the structure asphalt forms gradually. Each particle has been packed by asphalt and formulates cohesive force between asphalt and aggregate. The cohesive force increases with asphalt content increasing. Flexural characteristics reach the peak value in OAC of 5.5\%. Experiencing several F-T cycles, the flexural characteristics still are the best at the OAC compared with other asphalt-aggregate ratios.

With asphalt-aggregate ratio continually increasing, there is no more extra porosity to fill the asphalt and formed surplus asphalt. Compared with structure asphalt, surplus asphalt becomes free asphalt and lubricant. Aggregate particles will be "pushed away" and slide under the loading condition $[29,30]$. This leads to the flexural tensile strength reducing fiercely; however, flexural tensile strain decreases slowly.

If pores of mixture are too small, once water enters into the internal pores, it is hard to remove. Due to capillary action, when the water in the pores begins to freeze, its volume increases with the freezing of water, which produces water pressure. The water pressure makes the water in the pores continuously gather on the freezing peak surface under F-T cycles, which leads to the intensification of freezing effect. After several F-T cycles, porosity constantly increases with the accumulation of freezing impact. Flexural characteristics are reduced. The reduction extent of flexural characteristics is smaller at high asphalt content compared with the lower asphalt content. 
TABLE 3: Fitting results of the exponential model.

\begin{tabular}{lcccccccc}
\hline & \multicolumn{2}{c}{$\mathrm{a}$} & \multicolumn{2}{c}{$\mathrm{b}$} & & $\mathrm{c}$ & \multicolumn{2}{c}{ Statistics } \\
& Value & Error & Value & Error & Value & Error & Reduced $\chi^{2}$ & $R_{\text {adj }}^{2}$ \\
\hline Tensile strength & 11.38 & 0.23 & 4.46 & 0.89 & -0.32 & 0.12 & 0.20 & 0.866 \\
Tensile strain & 2943 & 40 & 460 & 87 & -0.19 & 0.08 & 3954 & 0.823 \\
\hline
\end{tabular}

TABLE 4: ANOVA results of exponential model.

\begin{tabular}{|c|c|c|c|c|c|c|}
\hline & & Df & Sum of squares & Mean square & $F$ value & Prob $>F$ \\
\hline \multirow{4}{*}{ Tensile strength } & Regression & 3 & 1179.481 & 393.1603 & 1927.163 & $6.04 E-08$ \\
\hline & Residual & 5 & 1.02005 & 0.20401 & & \\
\hline & Uncorrected total & 8 & 1180.501 & & & \\
\hline & Corrected total & 7 & 10.67235 & & & \\
\hline \multirow{4}{*}{ Tensile strain } & Regression & 3 & $7.48 E+07$ & $2.49 E+07$ & 6303.609 & $3.13 E-09$ \\
\hline & Residual & 5 & 19767.54 & 3953.507 & & \\
\hline & Uncorrected total & 8 & $7.48 E+07$ & & & \\
\hline & Corrected total & 7 & 156315.9 & & & \\
\hline
\end{tabular}

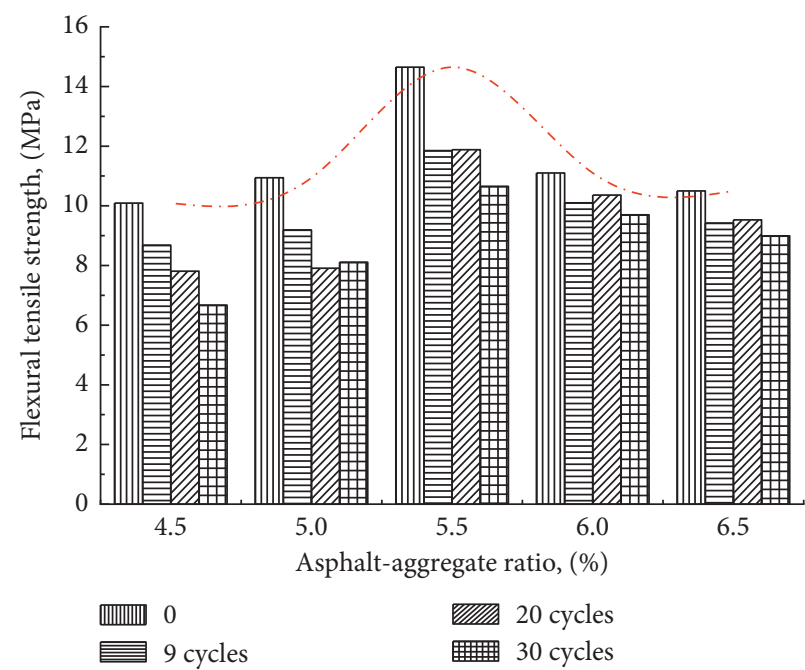

(a)

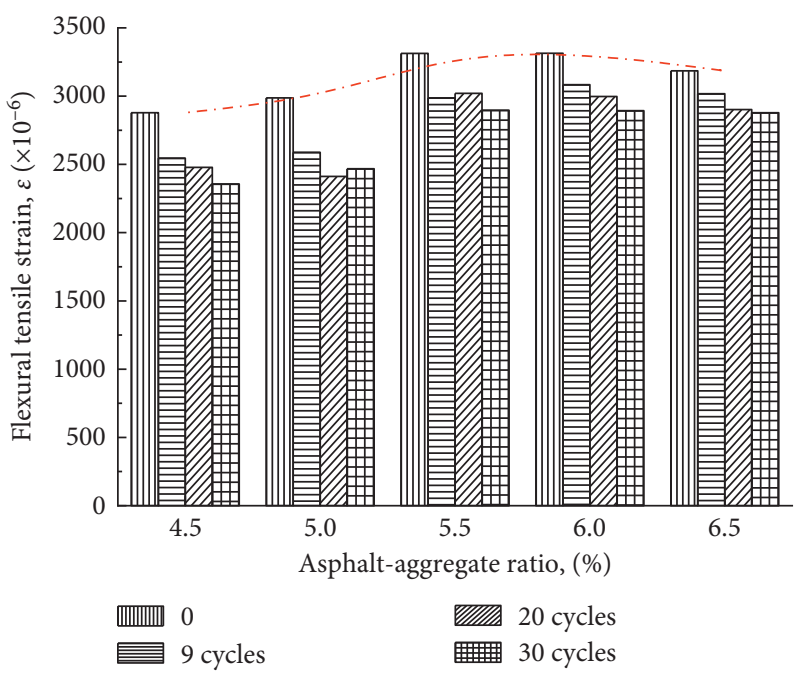

(b)

FIGURE 4: Relationship of flexural tensile characteristics and asphalt-aggregate ratio. (a) Flexural tensile strength. (b) Flexural tensile strain.

From the laboratory test data analysis, it is known that $\mathrm{F}-\mathrm{T}$ cycles and asphalt-aggregate ratio have influence on flexural tensile characteristics. ANOVA with a 0.05 level significance from statistic view is applied to illustrate the impacts of F-T cycles and asphalt-aggregate ratio. For F-T cycle factor, it has eight levels as shown in Figure 2; and asphalt-aggregate ratio has five levels as shown in Figure 4. For the same gradation and different asphalt-aggregate ratio mixture, results of ANOVA are shown in Table 5.

Table 5 shows that asphalt-aggregate ratio and F-T cycles have obvious influence on flexural tensile characteristics, respectively. More results imply that the interaction of asphalt-aggregate ratio and F-T cycles also has significant influence on flexural tensile characteristics. Results indicate that asphalt-aggregate ratio and F-T cycle are both important parameters, which impact on the performance of mixture. Therefore, the proper asphalt-aggregate ratio can be designed and got based on laboratory test, which can be used to limit the damage of F-T cycles.

3.2.1. Impact of Gradation. This paper chooses AC-10, AC13 , and $\mathrm{AC}-16$ to analyze the gradation impact on mixture flexural characteristics under F-T cycles.

As depicted in Figure 5, flexural characteristics of different gradations all show a declining trend as F-T cycles increase. In addition to the F-T cycles, the flexural characteristics of asphalt mixture are affected by many other factors, such as porosity, compaction, and uneven aggregate distribution, which inevitably cause some abnormal data in the flexural characteristics. However, after the F-T cycles, the overall trend of attenuation of the flexural characteristics remains unchanged. Flexural tensile characteristics of AC-13 are evident higher than the other two gradations. The 
TABLE 5: Two-factor ANOVA about F-T cycle and asphalt-aggregate ratio.

\begin{tabular}{lccccc}
\hline Sources of variation & SS & Df & MS & $P$ value & F-crit \\
\hline Asphalt-aggregate ratio & 197.10 & 4 & 49.27 & $4.05 E-63$ & $1.9 E-45$ \\
F-T cycles & 76.29 & 7 & 10.90 & 0.87 & $2.51 E-20$ \\
Interaction & 24.29 & 28 & 0.06 & 1.62 \\
Interior & 5.08 & 80 & & \\
Amount & 302.75 & 119 & & \\
\hline
\end{tabular}

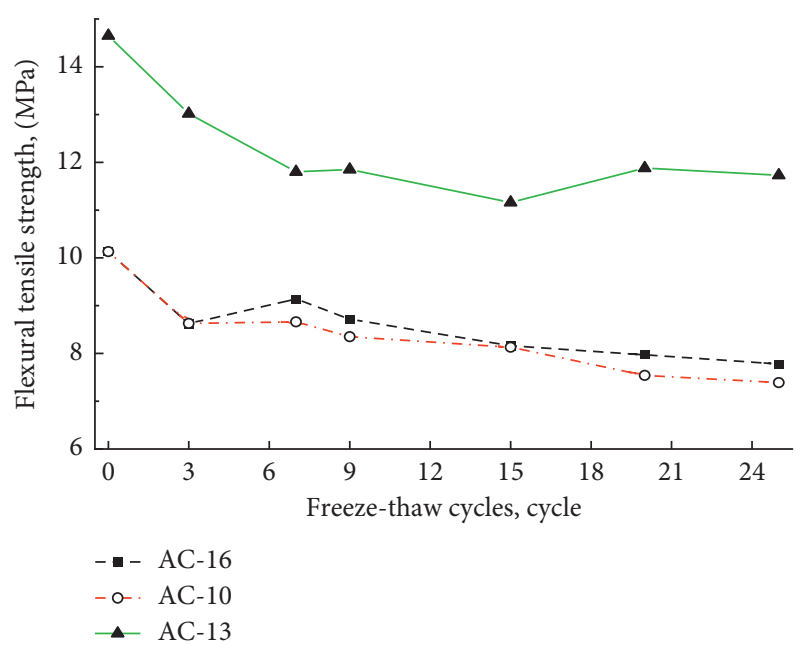

(a)

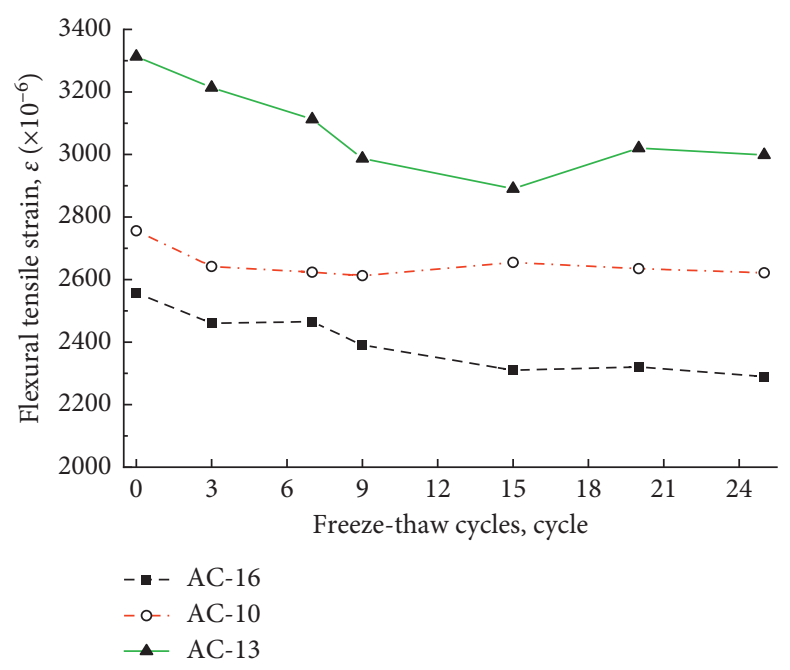

(b)

FIgURE 5: Flexural tensile characteristics and asphalt-aggregate ratio under different gradations. (a) Flexural tensile strength. (b) Flexural tensile strain.

difference of flexural tensile strength between AC-10 and AC-16 is small, and the change curves of flexural tensile strength have the same trend. For the flexural tensile strain between AC-10 and AC-16, the difference is small in the initial F-T cycles. With F-T cycles increasing, AC-10 tends to be stable, while AC-16 continually decreases, hence enlarging the difference between them.

Under loading conditions, loads are mainly transmitted along the aggregate particles, especially in large size particles; coarse aggregate plays an important role in bearing load. Under low-temperature loading, the strength of asphalt mixture mainly comes from coarse aggregate skeleton support. Asphalt binder effects are relatively reduced. With the maximum diameter decreasing, asphalt mixture becomes denser, and the resistance of low-temperature crack is improved to a certain extent. Additionally, the mixture defects are reduced. However, if the size of coarse aggregate is too small and the content of fine aggregate is too large, the strength of the mixture will also decrease. For AC-13 asphalt mixture, its nominal maximum aggregate size is between AC-10 and AC-16. Because AC-13 has high skeleton strength, high density of its mixture, and superior comprehensive performance, its flexural tensile strength and flexural tensile strain are superior to the other two gradations' mixture under F-T cycles.

The ANOVA method was applied to analyze the significance of F-T cycles and gradation change to flexural tensile strength characteristics. There are three levels of aggregate gradation, AC-10, AC-13, and AC-16. There are seven levels of F-T cycle factors: no F-T cycles, 3 cycles, 7 cycles, 9 cycles, 15 cycles, 20 cycles, and 25 cycles.

Flexural tensile characteristics were statistically analyzed with a level of significance of 0.05 . Results are shown in Table 6.

Gradation and F-T cycle have significant influence on flexural tension properties. The influence of gradation is greater than that of F-T cycles, which indicates that gradation is a major factor to determine the flexural tension properties of asphalt mixture.

ANOVA presents that all the F-T cycle, asphalt-aggregate ratio, gradation, and their interaction have significant influence on the flexural tensile properties of asphalt mixture. Flexural performance decreases evidently as the F-T cycles increase. Therefore, in cold regions, F-T cycle is another critical factor to determine the pavement durability and suitability besides the vehicle loads. Attention should be paid to F-T and other environment factors. Furthermore, appropriate asphalt-aggregate ratio and gradation can reduce the negative influence of F-T cycles on AC. In other words, they improve the resistance ability against complex climate.

3.2.2. Loss Ratio of Flexural Tensile Characteristics. As described before, flexural tensile characteristics of AC decline with the F-T cycles increasing. However, how to assess this 
TABLE 6: ANOVA about gradation and F-T cycle.

\begin{tabular}{lccccc}
\hline Sources of variation & SS & Df & MS & $P$ value & F-crit \\
\hline F-T cycles & 15.15 & 6 & 2.53 & $5.48 E-05$ \\
Gradation & 66.66 & 2 & 33.33 & $5.84 E-10$ \\
Error & 1.98 & 12 & 0.17 & 3.89 \\
Amount & 83.79 & 20 & & \\
\hline
\end{tabular}

TABLE 7: Fitting results of the logistic model.

\begin{tabular}{lcccccccccc}
\hline & \multicolumn{2}{c}{$a$} & \multicolumn{2}{c}{$b$} & \multicolumn{2}{c}{$x_{0}$} & \multicolumn{2}{c}{$p$} & \multicolumn{2}{c}{ Statistics } \\
& Value & Error & Value & Error & Value & Error & Value & Error & Reduced $\chi^{2}$ & $R_{\text {adj }}^{2}$ \\
\hline Tensile strength & -0.11582 & 0.48 & 0.24 & 0.06 & 1.86 & 4.25 & 1.21 & 1.75 & 0.001 \\
Tensile strain & $3.25 E-04$ & 0.03 & 0.11 & 0.02 & 5.24 & 2.04 & 2.36 & 1.87 & $4.36 E-04$ & 0.843 \\
\hline
\end{tabular}

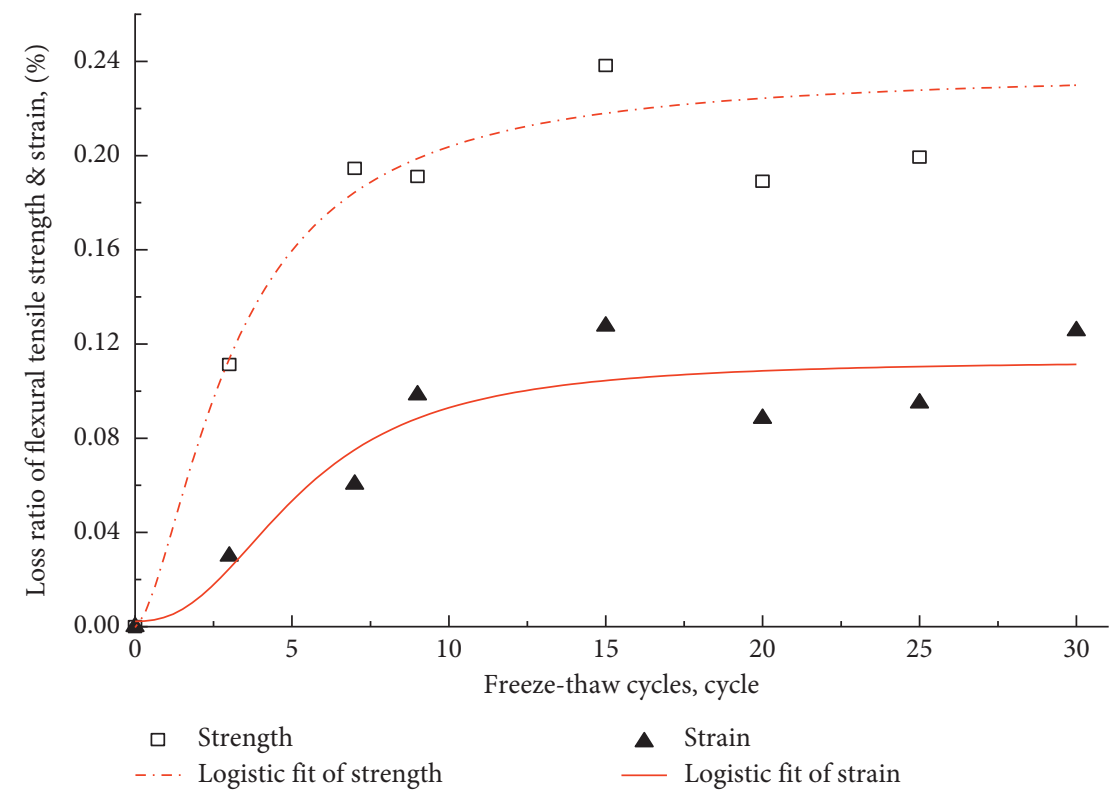

Figure 6: Relationship between loss ratio and F-T cycles.

variation effectively and conveniently is still a problem. The first pavement performance model was developed based on the data provided by the AASHO Road Test. The AASHO equation estimates deterioration based on a dimensionless parameter $g$ referred to as damage. The damage parameter was defined as the loss in serviceability at any given time.

$$
g_{t}=\frac{p_{0}-p_{t}}{p_{0}-p_{f}}=\left(\frac{N_{t}}{\rho}\right)^{b} \text {. }
$$

The recursive model is another popular model to simulate the performance deterioration. The following equation is applied from the beginning of the experiment:

$$
p_{t}=p_{0}+\alpha \sum_{s=0}^{s=t-1} N_{s}^{\sigma} \Delta N_{s+1},
$$

where $g_{t}$ is a dimensionless damage parameter; $p_{0}$ is initial service ability at time $t=0 ; p_{\mathrm{t}}$ is serviceability index at time $t$ (or load frequency, load variation); $p_{\mathrm{f}}$ is terminal serviceability index; $N_{\mathrm{t}}$ is cumulative number of equivalent $80 \mathrm{KN}$ single-axle loads applied until time $t ; N_{s}$ is the deterioration; $\Delta N_{s+1}$ is the increment of deterioration; and $\rho, b, \alpha, \sigma$ are parameters or functions to be estimated.Another general and flexible deterioration model is shown as follows:

$$
y=f(x)=a+b x^{c},
$$

where $y$ is a variable representing a measure of material quality; $x$ is a variable representing a measure of load (or traffic); $a$ is a parameter or a function that represents the initial condition; $b$ is a parameter or a function that represents the rate at which quality deteriorates with load frequency (or time, traffic); and $c$ is a parameter that represents the curvature of the function.

Performance deterioration functions (5) to (7) can be combined to predict the variation of performance. Based on these three functions, loss ratio has been applied to get the 
relationship of flexural tensile characteristics and F-T cycles; loss ratio formula is as follows:

$$
L_{i}=1-\left(\frac{y_{i}}{y_{0}}\right),
$$

where $L_{\mathrm{i}}$ is loss ratio of flexural tensile characteristics, $y_{0}$ represents the unconditioned flexural tensile characteristics, $y_{\mathrm{i}}$ represents the flexural tensile characteristics that change with F-T cycles, and subscript $i$ represents the F-T cycles, from 0 to 30 in this research. Flexural tensile characteristics $y_{\mathrm{i}}$ can be indicated by regression function (6).

Logistic model is a common sigmoid function; it is in relation to population growth. The logistic model is widely applied in neural networks, biology, probability, statistics, sociology, political science, and economics [12, 13]. Considering that the deterioration of loss ratio presents logistic curve with the increasing of F-T cycles, where deterioration is approximately exponential in initial stage, as saturation begins, the deterioration slows, and, at maturity, deterioration stops. Therefore, this paper uses modified logistic model to fit the deterioration trend, and the function is

$$
y=\frac{a-b}{1+\left(x / x_{0}\right)^{p}}+b
$$

where $y$ represents loss ratio flexural tensile characteristics; $x_{0}, a, b$, and $p$ are estimated parameters, $x_{0}$ is the center value, $a$ is the initial value, $b$ is the terminal value, and $p$ is the power and it is greater than zero. The estimation method of the logistic model is similar to that of the exponential model, applying the $\chi^{2}$ method to minimize the residual sum.

AC-13 of OAC of $5.5 \%$ is taken as an example to illustrate the loss ratio about flexural tensile strength and flexural tensile strain under different F-T cycles. The fitting results are shown in Table 7 , and the variation tendency is depicted in Figure 6.

Figure 6 illustrates that the logistic model and the loss ratio well reflect the deterioration of flexural tensile characteristics with the increasing of F-T cycles. The variation of deterioration is corresponding with the changes of flexural tensile characteristics.

The variation of loss ratio of flexural tensile strength is more intense than flexural tensile strain as F-T cycles increase, which implies that the flexural tensile strength of AC is more sensitive under F-T conditions. Previous research has indicated that the tensile strength of $\mathrm{AC}$ is related to fatigue cracking, moisture susceptibility, and the ability of resistance of thermal stress cracks. A higher tensile strength means that asphalt pavement can tolerate higher strains before failing (i.e., cracking). Therefore, this can explain why there are more cracks in cold regions, especially in frequent F-T cycles of cold plateau regions.

\section{Conclusions}

This work was conducted to explore the effect of F-T cycle on flexural tensile characteristics of asphalt mixture in laboratory. The main conclusions drawn from this study are summarized as follows.

When asphalt mixture suffered F-T impacts, the flexural tensile strength and flexural tensile strain will decline. Flexural tensile performance keeps declining as F-T cycles increase, which declines rapidly in the initial F-T cycles and then becomes gentle after 15-21 cycles.

Both asphalt content and gradation have an obvious influence on the flexural characteristics of asphalt mixture. In general, the higher asphalt content is, the slower degradation will be under F-T cycle. AC-13 has better flexural performance than AC-10 and AC-16, which indicates that AC-13 has better durable ability in low temperature and F-T conditions.

The flexural tensile properties get to peak value at the optimum asphalt content and obtain the slowest degradation correspondingly under F-T test.

The ANOVA results show that asphalt content, gradation, F-T cycles, and their interaction have significant impact on flexural tensile characteristics with a 0.05 level of significance from statistic view.

For the Qinghai-Tibet Plateau with severe weather conditions, it will improve the performance against low temperature if skeleton close-grained gradation of AC-13 and $5.5 \%$ or a little higher asphalt content is applied. Therefore, proper high asphalt content can reduce thermal cracks and moisture distress in cold regions, especially in high-frequency F-T zones.

\section{Data Availability}

All the data used to support the findings of this study are available from the corresponding author upon request.

\section{Conflicts of Interest}

The authors declare that they have no conflicts of interest.

\section{Acknowledgments}

The authors are grateful for the financial support by the Western Traffic Science Foundation of Department of Transportation in China, the National Natural Science Foundation of China (no. 51708044), the Shaanxi Province Science Foundation of China (no. 2020JM-251), the Fundamental Research Funds for the Central Universities (300102210211 and 300102218408), and the Tibet Science Foundation of China (nos. XZ 2019TL-G-04 and XZ 2019TL-G-05).

\section{References}

[1] Z. Zhang, Q. Wu, G. Jiang, S. Gao, J. Chen, and Y. Liu, "Changes in the permafrost temperatures from 2003 to 2015 in the Qinghai-Tibet plateau," Cold Regions Science and Technology, vol. 169, Article ID 102904, 2020.

[2] S. Wang, J. Chen, J. Zhang, and Z. Li, "Development of highway constructing technology in the permafrost region on the Qinghai-Tibet plateau," Science in China Series E: Technological Sciences, vol. 52, no. 2, pp. 497-506, 2009. 
[3] G. Cheng and T. Wu, "Responses of permafrost to climate change and their environmental significance, Qinghai-Tibet Plateau," Journal of Geophysical Research, vol. 112, 2007.

[4] G. Jiang, L. Wang, H. Yun, S. Gao, and Q. Wu, "Thermal influences of road engineering on permafrost underneath different surface condition in the Qinghai-Tibet Plateau," Cold Regions Science and Technology, vol. 173, Article ID 103028, 2020.

[5] W. Si, B. Tang, Y. Hu, B. Ma, Q. Ren, and S. Ge, "Variation and quantification of meteorological parameters along with the Qinghai-Tibet highway," China Sciencepaper, vol. 13, no. 07, pp. 727-731+736, 2018.

[6] L. Quan, B. Tian, K.-M. Niu, J.-D. Xie, Z. He, and Y.-H. Zhang, "Temperature variation properties of pavements and subgrades for high-grade roads on Qinghai-Tibet Plateau," Journal of Traffic and Transportation Engineering (China), vol. 17, no. 2, pp. 21-30, 2017.

[7] Q. B. Wu, Y. Sheng, Q. H. Yu, J. Chen, and W. Ma, "Engineering in the rugged permafrost terrain on the roof of the world under a warming climate," Permafrost Periglacial Process, vol. 12, 2020.

[8] J. Yuan, X. Pei, Q. Cheng, G. Zhang, and J. Chen, "Analysis on temperature variation regularity and slope temperature fielddeformation along sichuan-tibet expressway," Journal of Highway and Transportation Research and Development, vol. 36, no. 10, p. 33, 2019.

[9] K. Yang, Y. Mu, W. Ma, G. Bi, G. Li, and Y. Mao, "The evolution law of ground temperature field in permafrost roadbed of the Qinghai-Tibet plateau under climate warming," China Earthquake Engineering Journal, vol. 40, no. 4, pp. 734-744, 2018.

[10] W. Si, N. Li, B. Ma, J. Ren, H. Wang, and J. Hu, "Impact of freeze-thaw cycles on compressive characteristics of asphalt mixture in cold regions," Journal of Wuhan University of Technology (materials science) editorial department, vol. 30, no. 4, pp. 703-709, 2015.

[11] M. T. Chai, Y. H. Mu, J. M. Zhang, W. Ma, G. Liu, and J. B. Chen, "Characteristics of asphalt pavement damage in degrading permafrost regions: case study of the qinghai-tibet highway, China," Journal of Cold Regions Engineering, vol. 32, no. 2, p. 11, 2018.

[12] W. Ke, H. Chen, and Y. Lei, "Mechanical response of highgrade highway asphalt pavement in cold and high altitude area in Qinghai-Tibet Plateau," Journal of Chang'An University. Natural Science Edition, vol. 39, no. 1, pp. 34-43, 2019.

[13] B. Ma, X. Zhou, W. Si, N. Li, and S. Peng, "Study of the water stability and high temperature performance of asphalt mixtures in Qinghai-Tibet cold regions," Journal of Glaciology and Geocryology, vol. 37, no. 01, pp. 175-182, 2015.

[14] N. Li, W. Si, B. Ma, X. Zhou, and Y. Tian, "Impact of freezethaw cycles on flexural tensile characteristics of asphalt mixture in cold plateau regions," Journal of Jiangsu University (Natural Science Edition), vol. 36, no. 05, pp. 610-614, 2015.

[15] B. Teltayev, C. O. Rossi, G. Izmailova, and E. Amirbayev, "Effect of freeze-thaw cycles on mechanical characteristics of bitumens and stone mastic asphalts," Applied Sciences, vol. 9, no. 3, p. 458, 2019.

[16] Z. Li, Y. Tan, S. Wu, and F. Yang, "The effects of the freezethaw cycle on the mechanical properties of the asphalt mixture," Journal of Harbin Engineering University, vol. 35, no. 03, pp. 378-382, 2014.

[17] P. Kettil, G. Engström, and N.-E. Wiberg, "Coupled hydromechanical wave propagation in road structures," Computers \& Structures, vol. 83, no. 21-22, pp. 1719-1729, 2005.
[18] H. Xu, H. Shi, H. Zhang, H. Li, Z. Leng, and Y. Tan, "Evolution of dynamic flow behavior in asphalt mixtures exposed to freeze-thaw cycles," Construction and Building Materials, vol. 255, p. 119320, 2020.

[19] H. Xu, W. Guo, and Y. Tan, "Permeability of asphalt mixtures exposed to freeze-thaw cycles," Cold Regions Science and Technology, vol. 123, pp. 99-106, 2016.

[20] H. Wu, P. Li, T. Nian, G. Zhang, T. He, and X. Wei, "Evaluation of asphalt and asphalt mixtures' water stability method under multiple freeze-thaw cycles," Construction and Building Materials, vol. 228, p. 117089, 2019.

[21] JTG-E20-2011, Standard Test Material of Bitumen and Bituminous Mixtures for Highway Engineering, China Ministry of Transport, Beijing, China, 2011.

[22] L. X. Hua, F. P. Xiao, Y. T. Li et al., "A potential damage mechanism of rubberized cement under freeze-thaw cycle," Construction and Building Materials, vol. 252, p. 12, 2020.

[23] X. Zhang, M. Zhang, J. Lu, W. Pei, and Z. Yan, "Effect of hydro-thermal behavior on the frost heave of a saturated silty clay under different applied pressures," Applied Thermal Engineering, vol. 117, pp. 462-467, 2017.

[24] Y. Ji, G. Zhou, and M. R. Hall, "Frost heave and frost heavinginduced pressure under various restraints and thermal gradients during the coupled thermal-hydro processes in freezing soil," Bulletin of Engineering Geology and the Environment, vol. 78, no. 5, pp. 3671-3683, 2019.

[25] G. Xu, Y. Yu, D. Cai, G. Xie, X. Chen, and J. Yang, "Multi-scale damage characterization of asphalt mixture subject to freezethaw cycles," Construction and Building Materials, vol. 240, p. 117947, 2020.

[26] AASHTO, Resistance of Compacted Asphalt Mixtures to Moisture-Induced Damage, Vol. 283, AASHTO T, Washington, DC, USA, 2014.

[27] S. W. Goh, M. Akin, Z. You, and X. Shi, "Effect of deicing solutions on the tensile strength of micro- or nano-modified asphalt mixture," Construction and Building Materials, vol. 25, no. 1, pp. 195-200, 2011.

[28] D. Feng, J. Yi, D. Wang, and L. Chen, "Impact of salt and freeze-thaw cycles on performance of asphalt mixtures in coastal frozen region of China," Cold Regions Science and Technology, vol. 62, no. 1, pp. 34-41, 2010.

[29] X. Gong, P. Romero, Z. Dong, and D. S. Sudbury, "The effect of freeze-thaw cycle on the low-temperature properties of asphalt fine aggregate matrix utilizing bending beam rheometer," Cold Regions Science and Technology, vol. 125, pp. 101-107, 2016.

[30] S. Wu, J. Yang, R. Yang, J. Zhu, S. Liu, and C. Wang, "Investigation of microscopic air void structure of anti-freezing asphalt pavement with X-ray CT and MIP," Construction and Building Materials, vol. 178, pp. 473-483, 2018. 